\title{
Therapeutic effects and mechanism of ferulic acid and icariin in mammary gland hyperplasia model rats via regulation of the ERK pathway
}

\author{
Xiang $\mathrm{Li}^{1,2}$, Guobing Shi ${ }^{1}$ \\ ${ }^{1}$ College of life sciences and Biopharmaceuticals, Shenyang Pharmaceutical University, Shenyang, China; ${ }^{2}$ Pharmaceutical Department, Liaoning \\ Cancer Hospital, Shenyang, China \\ Contributions: (I) Conception and design: Both authors; (II) Administrative support: Both authors; (III) Provision of study materials or patients: \\ Both authors; (IV) Collection and assembly of data: Both authors; (V) Data analysis and interpretation: Both authors; (VI) Manuscript writing: Both \\ authors; (VII) Final approval of manuscript: Both authors. \\ Correspondence to: Guobing Shi. College of life sciences and Biopharmaceuticals, Shenyang Pharmaceutical University, 103 Wenhua Road, Shenhe \\ District, Shenyang, China. Email: sgb_syyk@163.com
}

Background: Ferulic acid (FA) and icariin (ICA), as the active compounds derived from Angelica sinensis and Epimedium brevicornum Maxim, respectively, have been shown to promote blood circulation, regulate menstruation, exhibit anti-inflammatory effects, and modulate estrogen levels. The aim of this study was to elucidate the possible mechanism of FA, ICA, and FA-ICA on estrogen-induced mammary gland hyperplasia (MGH) in rats.

Methods: Hematoxylin and eosin (HE) staining was performed to record the pathological changes in breast tissue, and enzyme-linked immunosorbent assay (ELISA) was utilized to determine the serum levels of luteinizing hormone (LH), PRL (prolactin), testosterone (T), estradiol (E2), follicular stimulating hormone (FSH), and progesterone (P). The message RNA (mRNA) expression levels of extracellular signal-regulated kinase 1 (ERK1), extracellular signal-regulated kinase 2 (ERK2), estrogen receptor (ER), and progesterone receptor (PR) were detected by real-time reverse transcription-polymerase chain reaction (RT-PCR) analysis. Furthermore, ER, phosphorylated-ER, PR, p-PR, ERK1/2, and p-ERK1/2 protein factors in the ERK signaling pathway were evaluated by Western blotting. Simultaneously, changes in breast height, diameter, body weight, and organ index were all recorded.

Results: We found that FA and ICA could modulate the degree of breast swelling, and reduce the body weight, thymus index, and uterus index. Furthermore, it could also block the pathological changes of MGH, including the number of mammary lobules, and the proliferation or expansion of acini and ducts. Moreover, treatment with FA and ICA remarkably down-regulated the serum expression levels of LH, PRL, T, and E2, as well as the mRNA expression levels of ER $\alpha, \mathrm{PR}, \mathrm{ERK} 1$, and ERK2. Additionally, protein levels of ER $\alpha$, $\mathrm{p}-\mathrm{ER} \alpha, \mathrm{PR}, \mathrm{p}-\mathrm{PR}, \mathrm{ERK} 1 / 2$, and p-ERK1/2 in breast tissue were down-regulated, however the serum content of FSH and $\mathrm{P}$ was up-regulated.

Conclusions: Our outcomes revealed that FA and ICA might potentially inhibit ER $\alpha$, PR, ERK1/2, and their phosphorylated proteins via the ERK signaling pathway, thus indicating a positive feedback control for the degree of breast hyperplasia.

Keywords: Ferulic acid (FA); icariin (ICA); mammary gland hyperplasia (MGH); extracellular signal-regulated kinase (ERK)

Submitted Jan 11, 2021. Accepted for publication Apr 22, 2021.

doi: 10.21037/atm-21-656

View this article at: http://dx.doi.org/10.21037/atm-21-656 


\section{Introduction}

Mammary gland hyperplasia (MGH), also known as cystic hyperplasia of the mammary gland, lobular hyperplasia, or mammary gland structural dysplasia, refers to a noninflammatory and non-neoplastic benign hyperplasia formed by excessive hyperplasia of the mammary duct, acinus, or fibrous tissue. Patients with MGH can feel pain and a mass in their breasts, accompanied by changes in the severity of their menstrual cycles and mood changes.

In recent years, the breast cancer carcinogenesis tendency of MGH has received increasing attention, as the risk of breast cancer is approximately $2 \%$. Not surprisingly, it is easily confused with early breast cancer. It has been reported that the 7-year cumulative canceration rate of patients with atypical breast hyperplasia is approximately $9.9 \%$. Most studies have shown that breast hyperplasia accounts for over $70 \%$ of all breast disease cases, and is the most common breast disease in middle-aged women. The incidence rate of breast hyperplasia has been increasing annually. Therefore, the prevention and treatment of breast hyperplasia has positive significance for the prevention of breast cancer.

According to modern medicine, the periodic imbalance of estrogen and progesterone levels in the body and the estrogen-induced stimulation of breast tissue are the main causes of breast hyperplasia. At the same time, estrogen in the occurrence of breast cancer can produce a carcinogenic effect by means of transformation or induced expression.

In recent years, traditional Chinese medicine (TCM) has made some progress in the treatment of MGH and its pathogenesis. Ferulic acid (FA) is one of the main active ingredients of TCMs such as Angelica sinensis and Chuanxiong. In the treatment of MGH with TCM, Angelica sinensis and Chuanxiong are the most commonly employed medicines and have been implemented clinically for many years. They have an important impact on promoting blood circulation and regulating menstruation. Previous studies have demonstrated that Epimedium exhibits a certain estrogen-like effect, and can significantly improve endometrial hyperplasia and thickening, thereby leading to uterine weight gain. Icariin (ICA) is the main effective component of Epimedium brevicornum Maxim, which may promote the secretion of estradiol by granulosa cells.

Therefore, the objective of this study was to explore the phytoestrogen activity and possible mechanism of action of FA and ICA, which are implemented in the treatment of MGH, so as to provide a reference for their clinical application, especially in patients with estrogendependent diseases such as breast hyperplasia (1-7). We present the following article in accordance with the ARRIVE reporting checklist (available at http://dx.doi. org/10.21037/atm-21-656).

\section{Methods}

\section{Materials and chemicals}

Estradiol (E2) benzoate injections and progesterone (P) injections were supplied by Ningbo SANSHENG Pharmaceutical Co., Ltd. (Ningbo, Zhejiang, China). Smoothing and moisturizing hair removal was obtained from Watsons (Todora, British Virgin Islands). E2, P, prolactin (PRL), testosterone (T), follicle-stimulating hormone (FSH), and luteinizing hormone (LH) enzymelinked immunosorbent assay (ELISA) kits were obtained from LianShuo Biotechnology Co., Ltd (Shanghai, China). The primary antibodies against ERK1/2, p-ERK1/2, estrogen receptor $\alpha(E R \alpha), p-E R \alpha$, progesterone receptor $(\mathrm{PR}), \mathrm{p}-\mathrm{PR}$, and $\beta$-actin, as well as all of the secondary antibodies were obtained from Cell Signaling Technology Inc. (Danvers, USA). The bicinchoninic acid (BCA) protein assay kit and protein extraction kit were obtained from Keygen Biotech Inc. (Nanjing, China). The animal total RNA extraction kit was obtained from Tiandz Inc. (Beijing, China). FA and ICA were obtained from Alfabiotech Inc. (Chengdu, China). PrimeScriptTM RT reagent kit was purchased from Takara Bio Inc. (Shiga, Japan).

\section{Animals and treatments}

Seventy virgin female Sprague Dawley (SD) rats (180-220 g, 7-8 weeks old, license number: SCXK2015-0001) were commercially supplied by Liaoning Changsheng Biotechnology Co., Ltd (Liaoning, China). The rats were housed in an animal experimental center (temperature, $25 \pm 1{ }^{\circ} \mathrm{C}$; humidity, $65 \% \pm 5 \%$ ) under a $12 \mathrm{~h}$ light/dark cycle for at least 1 week prior to the experiments. They were fed with standard food and water ad libitum. All experimental protocols were approved by the Institutional Animal Care and Use Committee at the Liaoning University of Traditional Chinese Medicine and in accordance with the National Institutes of Health guidelines for the Care and Use of Laboratory Animals.

The rats were randomly divided into seven groups $(\mathrm{n}=10$ in each group). Rats in the normal matched group were intramuscularly injected with $0.9 \%$ saline $(0.5 \mathrm{~mL} / \mathrm{kg} / \mathrm{d})$ for 30 days, while rats in the other groups were administered with estrogen $(0.5 \mathrm{mg} / \mathrm{kg} / \mathrm{d})$ intramuscularly for 25 days, 
followed by progestogen $(5 \mathrm{mg} / \mathrm{kg} / \mathrm{d})$ for another 5 days to induce MGH. After that, we chose two rats randomly and prepared paraffin-sectioned hematoxylin and eosin (HE)stained breast tissues to confirm the success or failure of the MGH model. Rats in the MGH group received $0.9 \%$ saline $(0.5 \mathrm{~mL} / \mathrm{kg} / \mathrm{d})$. Tamoxifen (TMXF, positive Western medicine group, $5 \mathrm{mg} / \mathrm{kg} / \mathrm{d}$ ), Rupixiao (RPX, positive Chinese medicine group, $5 \mathrm{mg} / \mathrm{kg} / \mathrm{d}$ ), FA (FA group, $5 \mathrm{mg} / \mathrm{kg} / \mathrm{d}$ ), and ICA (ICA group, $5 \mathrm{mg} / \mathrm{kg} / \mathrm{d}$ ) were dissolved in normal $0.9 \%$ saline and intragastrically administered to the rats for 30 days. Under the same conditions, rats in the mixed group were treated with both FA $(2.5 \mathrm{mg} / \mathrm{kg} / \mathrm{d})$ and ICA $(2.5 \mathrm{mg} / \mathrm{kg} / \mathrm{d})(8)$.

\section{Sample collection}

Twelve hours after the last administration, all experimental rats were anesthetized with $2.5 \%$ pentobarbital solution and euthanized by cervical dislocation. Blood samples were collected from the abdominal aorta. Once the blood clotted at room temperature, the serum was separated within $10 \mathrm{~min}$ by centrifugation at $3,000 \mathrm{r} / \mathrm{min}$ for $5 \mathrm{~min}$ at $4{ }^{\circ} \mathrm{C}$. Half of the collected mammary gland tissue samples were fixed with $10 \%$ formaldehyde for pathological examination.

\section{Body weight, nipple height and diameter, and organ indicators}

The body weight was recorded on the first day of dosing and thereafter documented once a week until termination. The height and diameter of the nipple of all rats were documented after the administration. According to the following formula, calculate the organ index (breast) by dividing the breast weight by the body weight (8):

Organ index $=\left(W_{\text {organ }} \times 10\right) / W_{\text {body }}$ where $W_{\text {organ }}$ and $W_{\text {body }}$ stand for the average weights of the breasts and bodies of the rats, respectively.

\section{Histopathological evaluations}

Tissues of mammary gland from all groups were embedded in paraffin, sectioned into thin slices, and then stained with $\mathrm{HE}$ and observed using optical microscopy.

\section{ELISA}

Serum concentrations of E2, P, PRL, T, FSH, and LH in the MGH rats were tested. All measurements were obtained by commercial detection kits according to the manufacturer's instructions (LianShuo Biotechnology Co., Ltd, Shanghai, China).

\section{RNA isolation and quantitative real-time PCR}

Quantitative real-time PCR was performed to determine the gene expression of ERK1, ERK2, ER, and PR. Total RNA was extracted and purified from mammary glands using Trizol according to the manufacturer's instructions (Abcam, Cambridge, UK). The first-strand complementary DNA (cDNA) was synthesized from $1 \mu \mathrm{g}$ RNA with the reverse transcription reagent kit (Takara, Shiga, Japan). Next, $2 \mu \mathrm{g}$ of cDNA was added to the quantitative real-time PCR system in a CG-05 instrument (Heal Force, Hong Kong, China). Primers were designed with Primer 5.0 design software and listed (Table 1). Reaction conditions were as follows: $95{ }^{\circ} \mathrm{C}$ for $30 \mathrm{~s}$, and 40 cycles $\left(95^{\circ} \mathrm{C}\right.$ for $50 \mathrm{~s}, 60^{\circ} \mathrm{C}$ for $\left.30 \mathrm{~s}\right)$. All experiments were repeated in triplicate. The cycle threshold $(\mathrm{Ct})$ value was detected and the relative expression of the target gene was calculated according to $2^{-\Delta \Delta \mathrm{Ct}} \operatorname{method}(9)$.

\section{Western blotting}

Weigh the breast tissue and add appropriate amount of tissue protein extraction lysate according to the kit instructions (Invent Biotechnologies, Inc., Eden Prairie, USA). Immediately place it on ice to grind and homogenize; centrifuge at $12,000 \mathrm{r} / \mathrm{min}$ at $4{ }^{\circ} \mathrm{C}$ for $10 \mathrm{~min}$ to extract the total protein. The BCA method determines the protein concentration. The protein was separated by polyacrylamide gel electrophoresis(SDS-PAGE), transferred to the PVDF membrane, blocked at $4{ }^{\circ} \mathrm{C}$ for $3 \mathrm{~h}$, and added the primary antibody overnight at $4{ }^{\circ} \mathrm{C}$ (ER, p-ER, PR, p-PR, ERK1/2, $\mathrm{p}$-ERK1/2, and $\beta$-actin). After washing, add secondary antibody $(1: 5,000)$ and incubate for $2 \mathrm{~h}$ at $4{ }^{\circ} \mathrm{C}$ on a shaker, and then detect protein level by gel imaging analysis system. Using $\beta$-actin as the internal reference, the image $\mathrm{J}$ software was employed to collect the gray value of the band, and the ratio of the gray value of the target protein band and the gray value of the internal control band was taken as the relative expression level of the protein.

\section{Statistical analysis}

All values were presented as the mean \pm standard deviation of at least three independent experiments. Differences present in a set of data were tested by one-way analysis 
Table 1 Rat gene-specific primers

\begin{tabular}{|c|c|c|c|c|}
\hline Gene symbol & Reference sequence & Primer & Sequence $\left(5^{\prime}-3^{\prime}\right)$ & Product size (bp) \\
\hline ERK1 & $\begin{array}{l}\text { NM_fifty thousand six hundred } \\
\text { and eighty-nine }\end{array}$ & Reverse & CСACATCCAATCACCCACAC & 131 \\
\hline \multirow[t]{2}{*}{ ERK2 } & \multirow{2}{*}{$\begin{array}{l}\text { NM_one hundred and sixteen } \\
\text { thousand five hundred and ninety }\end{array}$} & Forward & GACACTTGGCATGAAGAGGAAAG & \multirow[t]{2}{*}{115} \\
\hline & & Reverse & GAGGGTGAGGGCAGTATGGA & \\
\hline$E R$ & $\begin{array}{l}\text { NM_twenty-four thousand eight } \\
\text { hundred and ninety }\end{array}$ & Reverse & AGGATCTCCAACCAGGCACAC & 130 \\
\hline \multirow[t]{2}{*}{$P R$} & \multirow{2}{*}{$\begin{array}{l}\text { NM_twenty-five thousand one } \\
\text { hundred and fifty-four }\end{array}$} & Forward & TCGTACAAGCATGTCAGTGGACAG & \multirow[t]{2}{*}{105} \\
\hline & & Reverse & CATGGTAAGGCACAGCGAGTAGAA & \\
\hline$\beta$-actin & $\begin{array}{l}\text { NM_eighty-one thousand eight } \\
\text { hundred and twenty-two }\end{array}$ & Forward & CTCTGTGTGGATTGGTGGCT & 139 \\
\hline
\end{tabular}

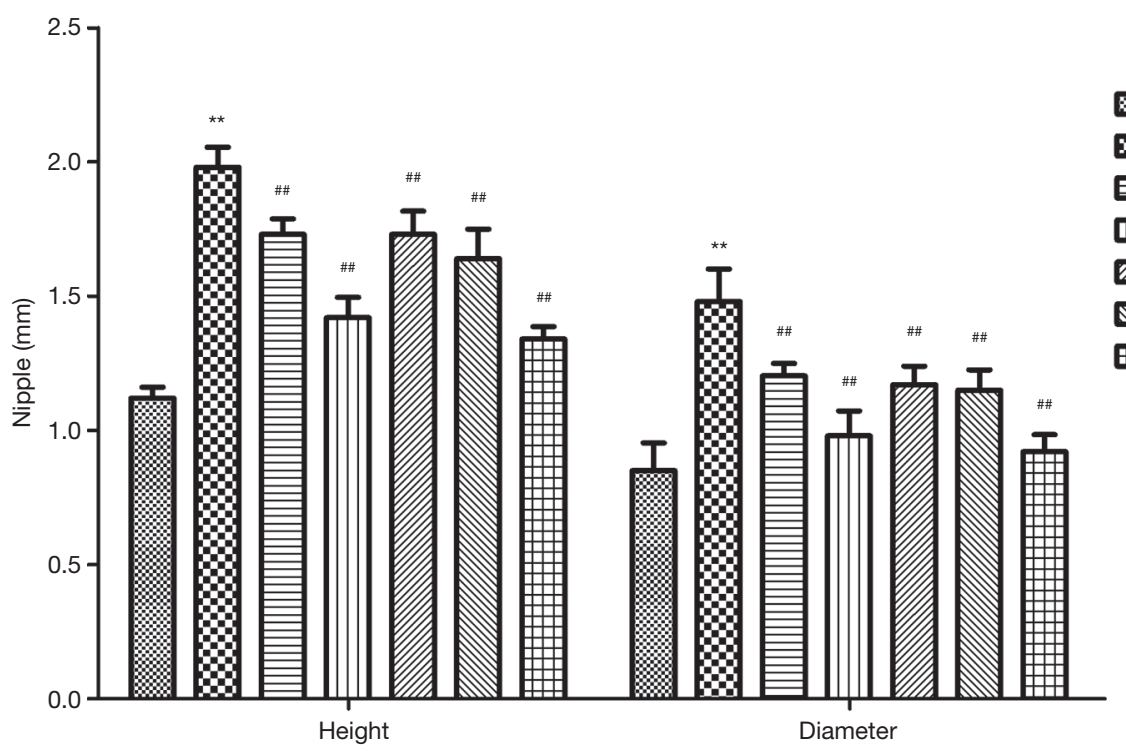

Figure 1 Measurement outcomes of nipple height and breast diameter of rats $(\bar{x} \pm \mathrm{S}, \mathrm{n}=10) .{ }^{* *} \mathrm{P}<0.01$ vs. blank matched group; ${ }^{* \#} \mathrm{P}<0.01$ vs. model group.

of variance (ANOVA) followed by Tukey's multiple comparison. $\mathrm{P}<0.05$ was considered statistically significant. Statistical analysis was performed using GraphPad Prism software version 8.0.

\section{Results}

\section{FA and ICA restrained nipple height and diameter in MGH rats}

All experiments provided completed outcome data. In the blank matched group, the nipples of rats were small granules that were pasted on the skin, soft, and some of them were slightly raised. As shown in Figure 1, the nipple height and breast diameter of rats in the model group were significantly augmented $(\mathrm{P}<0.01)$ compared with the blank matched group. However, compared with the model group, the nipple height and breast diameter of each experimental group had a distinct suppress $(\mathrm{P}<0.01)$. From these outcomes, we can conclude that FA, ICA, and their mixture could improve the degree of breast swelling in rats with mammary hyperplasia. 


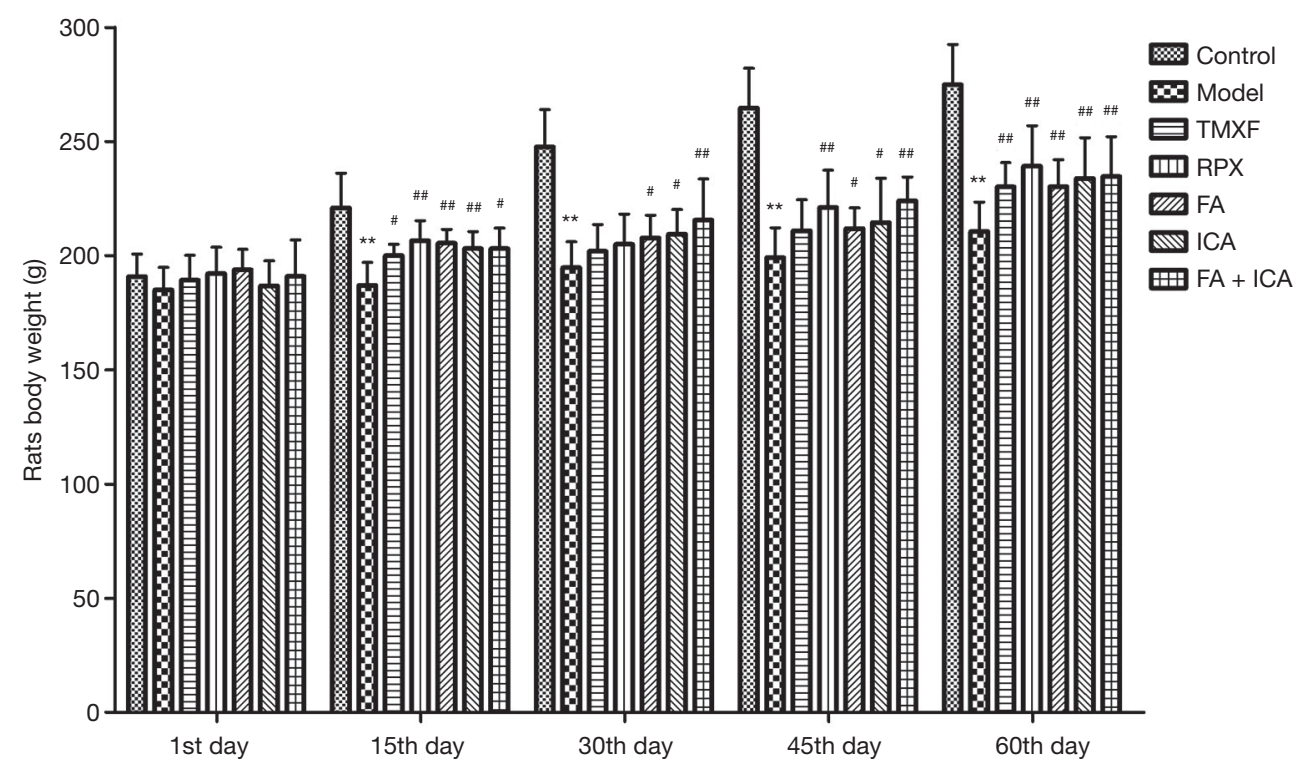

Figure 2 Effects of ferulic acid and icariin on the weight of rats $(\bar{x} \pm \mathrm{s}, \mathrm{n}=10)$. ${ }^{* *} \mathrm{P}<0.01$ vs. blank matched group; ${ }^{\#} \mathrm{P}<0.05$ and ${ }^{\# \#} \mathrm{P}<0.01$ vs. model group.

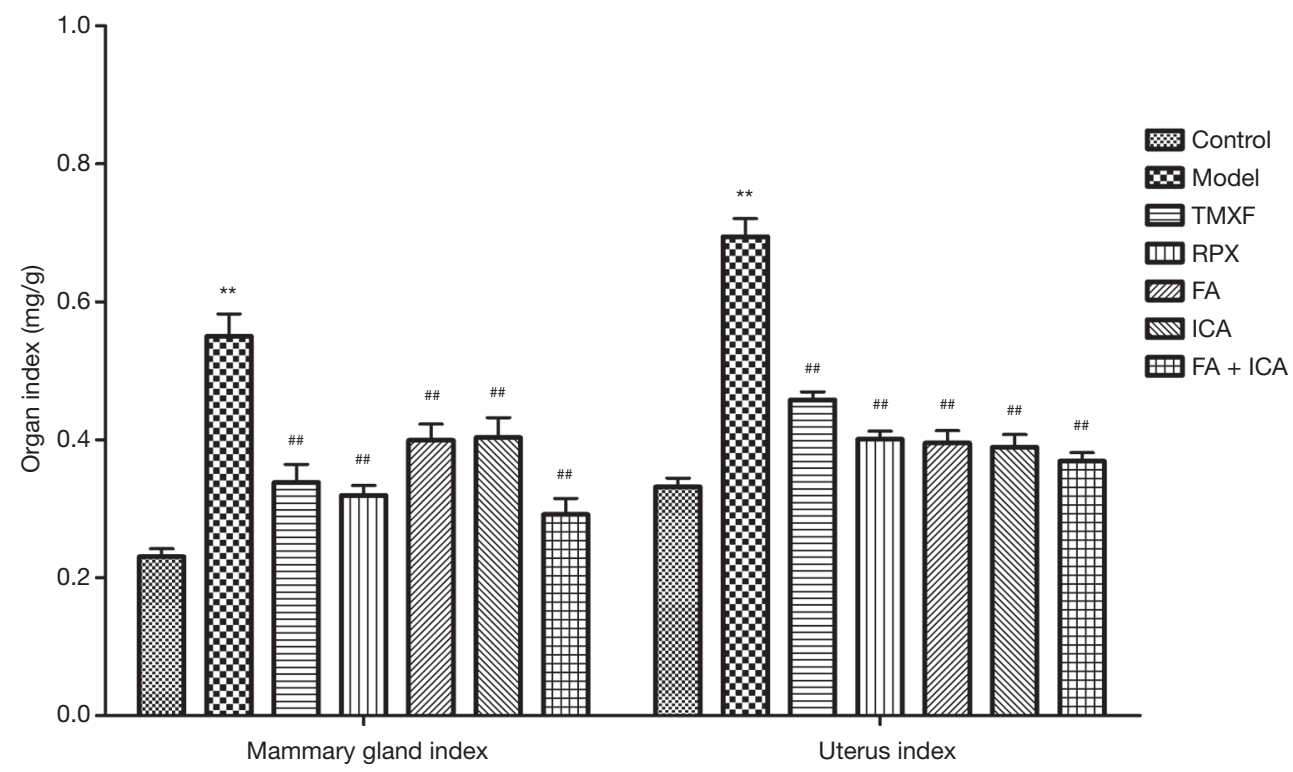

Figure 3 Effects of ferulic acid and icariin on the organ coefficients of rats $(\bar{x} \pm \mathrm{s}, \mathrm{n}=10)$. ${ }^{* *} \mathrm{P}<0.01$ vs. blank matched group; ${ }^{\# \#} \mathrm{P}<0.01 v s$. model group.

\section{FA and ICA attenuate d the body weight and organ indexes MGH rats}

As shown in Figures 2 and 3, there was no distinct difference in the initial body weight of the rats in each group $(\mathrm{P}>0.05)$. However, after 60 days of modeling and administration, the outcomes exhibited that the body weight of rats in the model group was markedly lower $(\mathrm{P}<0.01)$, and the mammary gland and uterine indexes were distinctly boosted $(\mathrm{P}<0.01)$ compared with the blank matched group. Simultaneously, the body weight of each treatment group was notably enhanced $(\mathrm{P}<0.01)$, and the mammary gland and uterine indexes were obviously suppressed $(\mathrm{P}<0.01)$. 


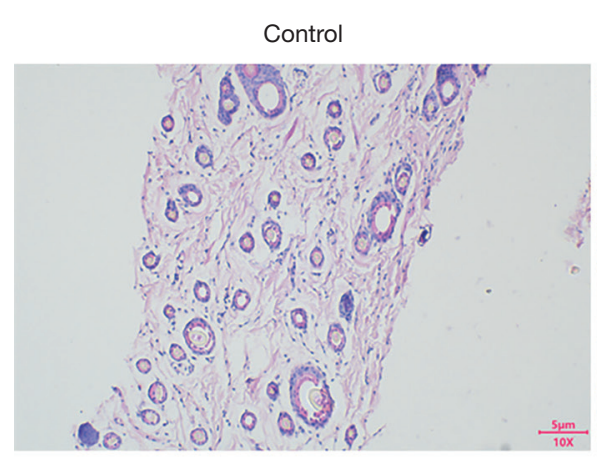

$\mathrm{RPX}$

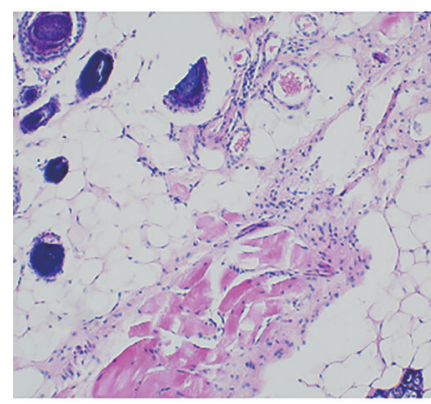

$F A+I C A$

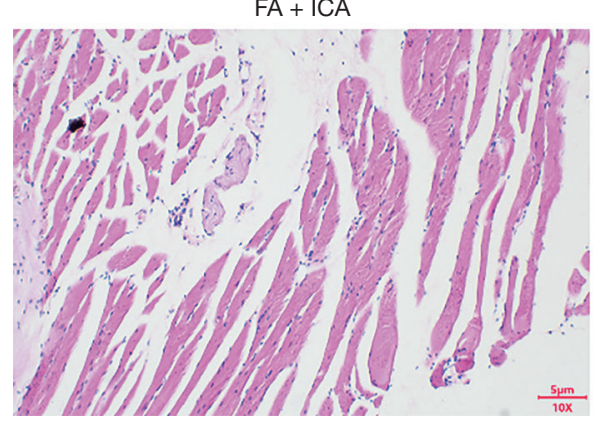

Figure 4 Pathological morphology of mammary gland tissue was observed by microscope (HE staining, $\times 100$ ).

\section{FA and ICA protected mammary gland tissue pathomorphology in MGH rats}

The outcomes of HE staining exhibited that there were no histopathological alterations in the mammary glands of the blank group rats (Figure 4 and Table 2). In contrast to the model group, the proliferative degree of mammary lobules, and the volume and number of acini and ducts obviously augmented. There was also thickening of the glandular epithelium and dilation of the duct. However, there were significant differences in the positive drug group (Tamoxifen and Rupixiao). The number of lobular acini and dilated ducts was significantly reduced, etc. In the treatment groups (FA, ICA, and their mixture), all of these indexes were distinctly ameliorated compared to the positive drug group.

\section{FA and ICA ameliorated the serum sex hormone levels of MGH rats}

In the model group, the serum levels of LH, PRL, $\mathrm{T}$, and E2 were obviously enhanced, while the serum contents of FSH and P were notably attenuate $\mathrm{d}$ $(\mathrm{P}<0.01$ vs. the blank group). However, compared to the matched group, both the positive drug group (TMXF and RPX) and the administration group (FA, ICA, and their mixture) could significantly reduce the serum levels of LH, PRL, T, and E2 to different degrees and increase the serum content of FSH and $\mathrm{P}(\mathrm{P}<0.01)$. The outcomes are shown in Figure 5. 
Table 2 Effects of ferulic acid and icariin on the pathological changes of mammary glands of rats in each group $(\mathrm{n}=10)$

\begin{tabular}{|c|c|c|c|c|}
\hline Group & Grade I (number) & Grade II (number) & Grade III (number) & Grade IV (number) \\
\hline Model & 0 & 0 & 2 & 8 \\
\hline TMXF & 1 & 7 & 1 & 1 \\
\hline RPX & 1 & 8 & 1 & 0 \\
\hline ICA & 0 & 5 & 5 & 0 \\
\hline $\mathrm{FA}+\mathrm{ICA}$ & 1 & 5 & 4 & 0 \\
\hline $\begin{array}{l}\text { Classification } \\
\text { description }\end{array}$ & $\begin{array}{l}\text { The number of acini was } \\
\text { little; the vessel was not } \\
\text { dilated; and the tissue } \\
\text { structure was clear }\end{array}$ & $\begin{array}{l}\text { The number of acini was } \\
\text { augmented; the vessel was } \\
\text { occasionally dilated; and } \\
\text { the tissue structure was not } \\
\text { clear compared to Grade I }\end{array}$ & $\begin{array}{l}\text { The number of acini was } \\
\text { increased; the vessel was } \\
\text { partly dilated; and the } \\
\text { tissue structure was not } \\
\text { clear compared to Grade II }\end{array}$ & $\begin{array}{c}\text { The number of acini } \\
\text { boosted significantly; the } \\
\text { duct was markedly dilated; } \\
\text { and the boundary was not } \\
\text { much clearer compared to } \\
\text { Grade III }\end{array}$ \\
\hline
\end{tabular}

\section{FA and ICA modulated the mRNA expression of ERK1, ERK2, ER, and PR in MGH rats}

We observed that the mRNA expression of ER $\alpha, P R$, ERK1, and ERK2 in the model group were significantly boosted compared to the blank group $(\mathrm{P}<0.01)$ (Figure 6). Conversely, as expected, the mRNA expression of ER $\alpha$, PR, ERK1, and ERK2 in the positive drug group (TMXF and RPX) and the administration group (FA, ICA, and their mixture) were markedly suppressed compared to the model group $(\mathrm{P}<0.01)$.

\section{FA and ICA modulated ER, $p-E R, P R, p-P R, E R K 1 / 2$, and p-ERK1/2 in MGH model rats}

Western blotting was employed to investigate the effects of FA and ICA on the level of ER, p-ER, PR, p-PR, ERK1/2, and p-ERK1/2 in MGH model rats. The levels of the abovementioned index were notably up-regulated in the model group compared to the matched group $(\mathrm{P}<0.01$, Figure 7$)$. Meanwhile, compared with the model group, the positive drug group (TMXF and RPX) and administration group (FA, ICA, and their mixture) either absolutely or relatively downregulated the levels of ER, p-ER, PR, p-PR, ERK1/2, and p-ERK1/2 $(\mathrm{P}<0.05$ and $\mathrm{P}<0.01)$, and the ratios of $\mathrm{p}-\mathrm{ER} \alpha /$ $\mathrm{ER} \alpha, \mathrm{p}-\mathrm{PR} / \mathrm{PR}, \mathrm{p}-\mathrm{ERK} 1 / 2$ and ERK1/2 $(\mathrm{P}<0.01)$.

\section{Discussion}

FA is an active compound derived from Angelica sinensis
Ligusticum chuanxiong hort, Ferula sinkiangensis K. M. Shen etc., and is commonly employed by patients to treat numerous gynaecological disorders. It has the effect of promoting blood circulation and regulating menstruation (10). ICA is the primary active component of Epimedium brevicornum Maxim and has a wide range of biological effects, including anti-inflammatory, anti-oxidative stress, and anti-tumor effects (11). In this study, a TMXF and RPX tablet, which has been shown to be highly effective in treating MGH was employed as the reference drug (positive control), and estrogen combined with progestogen were intramuscularly injected into the MGH model rats, in order to explore the possible mechanisms of FA and ICA on MGH.

Presently, there is a consensus that the height and diameter of rats' nipples could reflect the changes in the length and diameter of the mammary duct. Moreover, changes in the diameter and height of the second and third pair nipples from the chest down in rats reflect the physiological and pathological changes of the human breast to a certain extent. In our study, we found that FA, ICA, and their combination reduced the height and diameter of the nipple to different degrees, and there was a good recovery in the numbers of lobules, numbers of acinars, lobule volumes, expansion of ducts and lobules, and the exuberant secretion. Thus, they can obviously improve the histopathological changes of MGH, and inhibit MGH in model rats (12).

MGH is a breast pathology that involves hyperplasia of the mammary gland and ductal extension (among other effects). Mammary gland tissue is primarily regulated by 
A

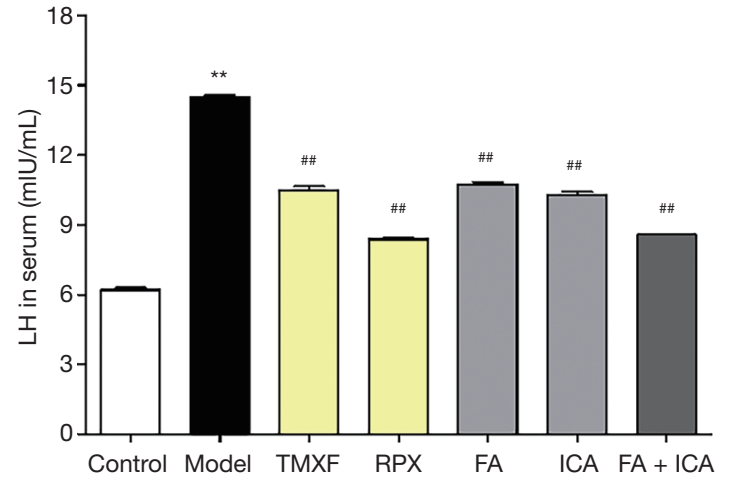

C

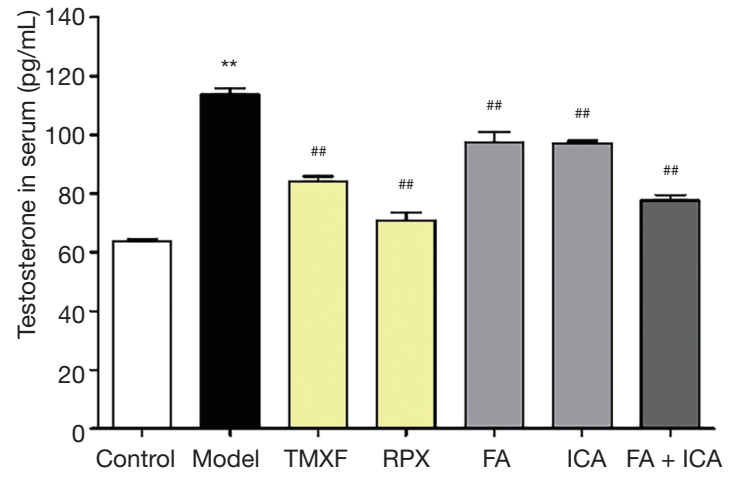

$E$

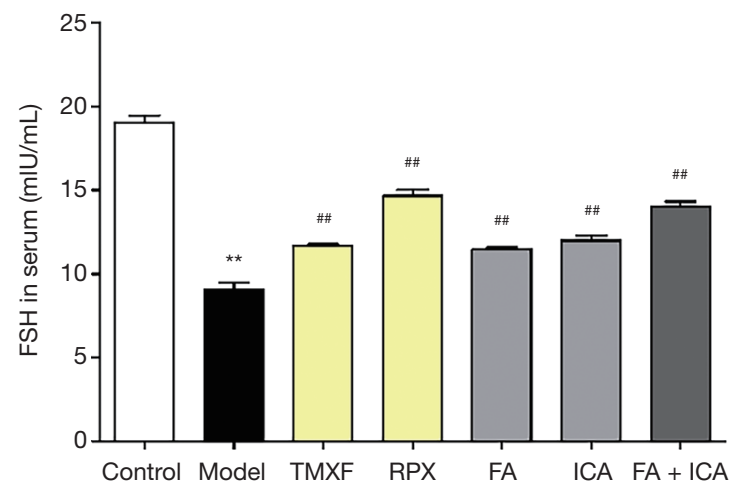

B

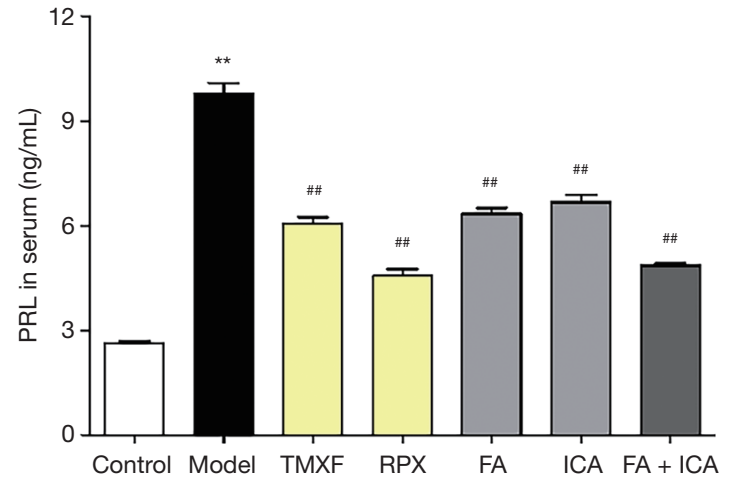

$\mathrm{D}$

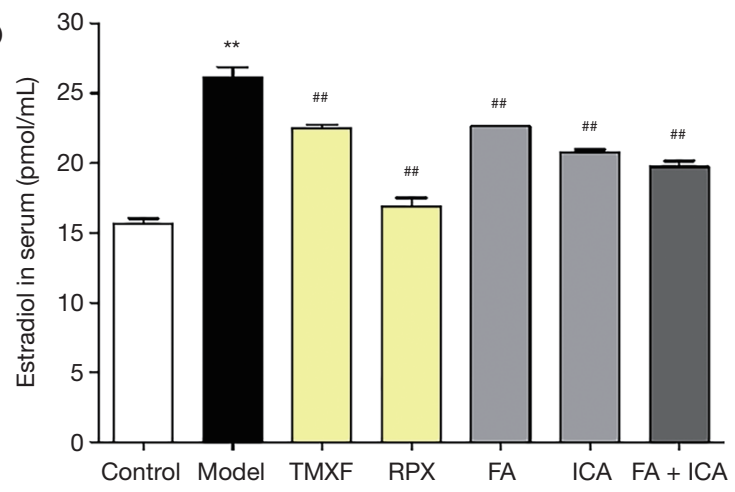

$\mathrm{F}$

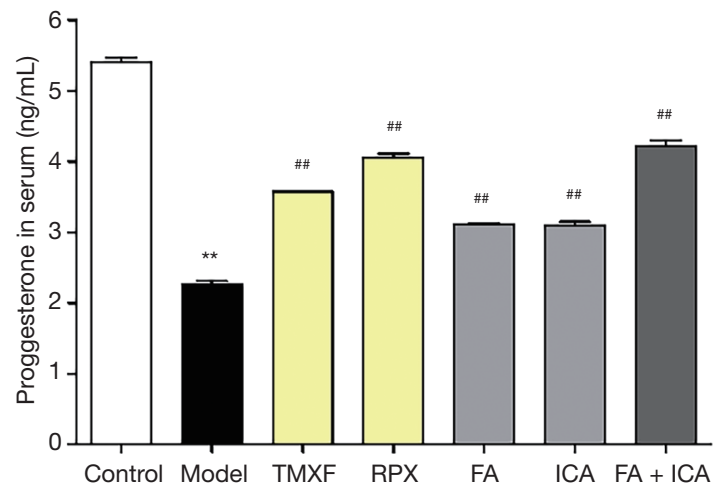

Figure 5 Effects of ferulic acid and icariin on the LH (A), PRL (B), Testosterone (C), Estradiolin (D), FSH (E) and Proggesterone (F) levels in serum of rats $(\bar{x} \pm s, \mathrm{n}=10)$. ${ }^{*} \mathrm{P}<0.01$ vs. blank matched group; ${ }^{\# \#} \mathrm{P}<0.01$ vs. model group.

estrogen, P, PRL, and other hormones. Estrogen regulates the development of ductal tissue, while $\mathrm{P}$ mediates the branching of milk ducts and the development of lobules. Hormone levels can be a type of reactivating disease and an effective treatment option. With the changes in hormone levels during the menstrual cycle, the normal breast tissue structure has a periodic change of physiological proliferation and involution. Periodic hormone secretion disorder and augmented sensitivity of breast tissue to hormones are the main causes of breast hyperplasia $(13,14)$.

The enhanced PRL can also directly stimulate mammary gland tissue, and further inhibit $\mathrm{P}$ secretion in the luteal phase. At the same time, the absolute or relative increase in $\mathrm{E} 2$, in addition to the long-term deficiency of $\mathrm{P}$, outcomes in an imbalanced E2/P ratio, which is conducive to enhanced estrogen levels and causes excessive hyperplasia and subinvolution of the mammary glandular parenchyma (15).

In our study, the serum levels of E2, LH, PRL, and T in the model group were distinctly higher compared to those in the blank matched group. Moreover, the ratio of E2/P, which confirmed that the imbalance in the $\mathrm{E} 2 / \mathrm{P}$ ratio was one of the causes of MGH, was also notably augmented. 
A

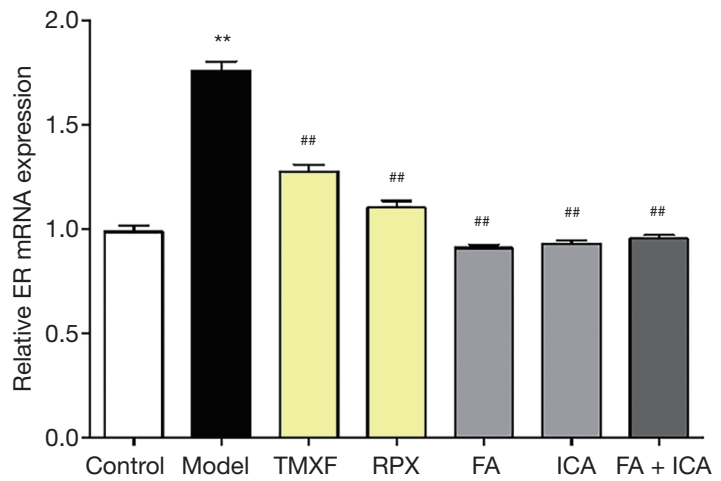

C

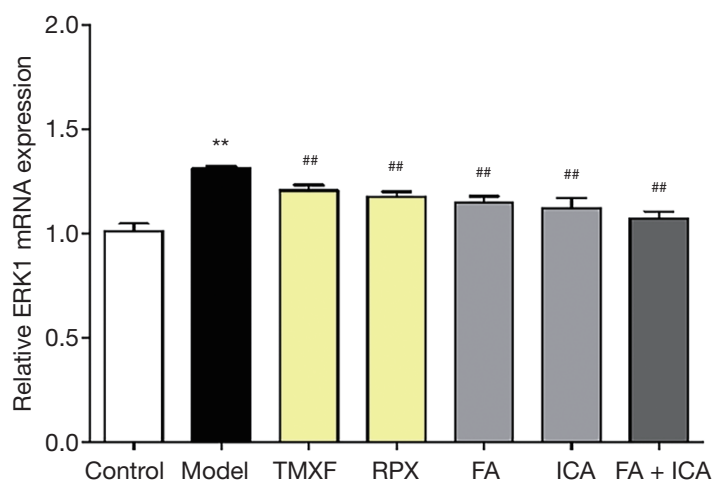

B
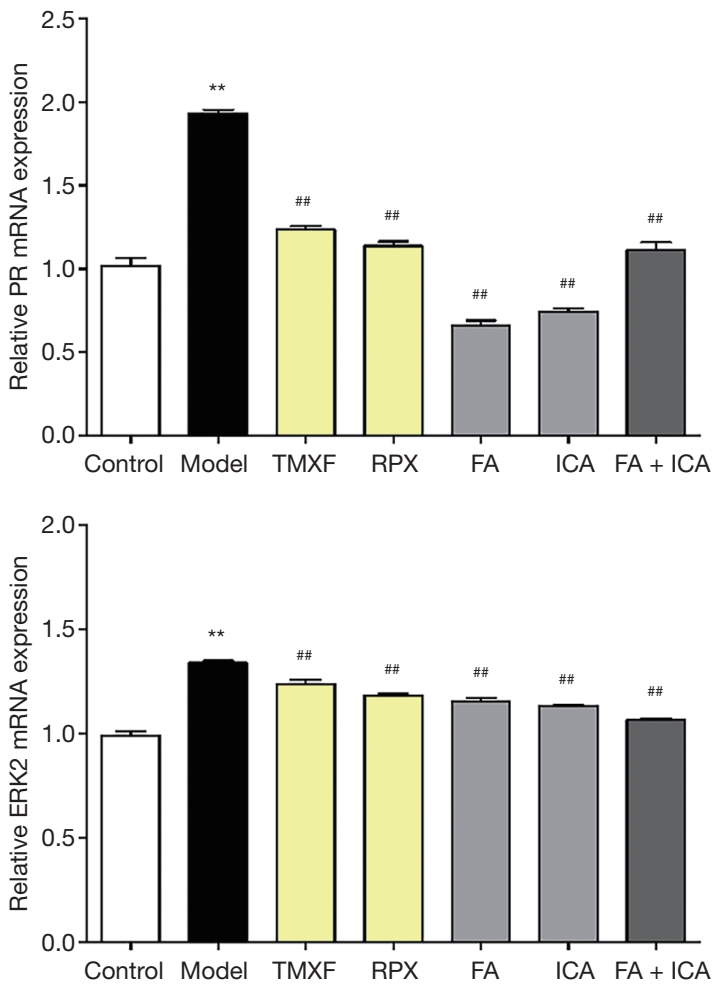

Figure 6 Effects of ferulic acid and icariin on the mRNA expressions in the mammary glands of rats in each group ( $\bar{x} \pm s, n=10)$. (A) ER; (B)

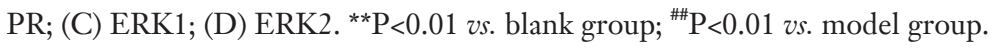

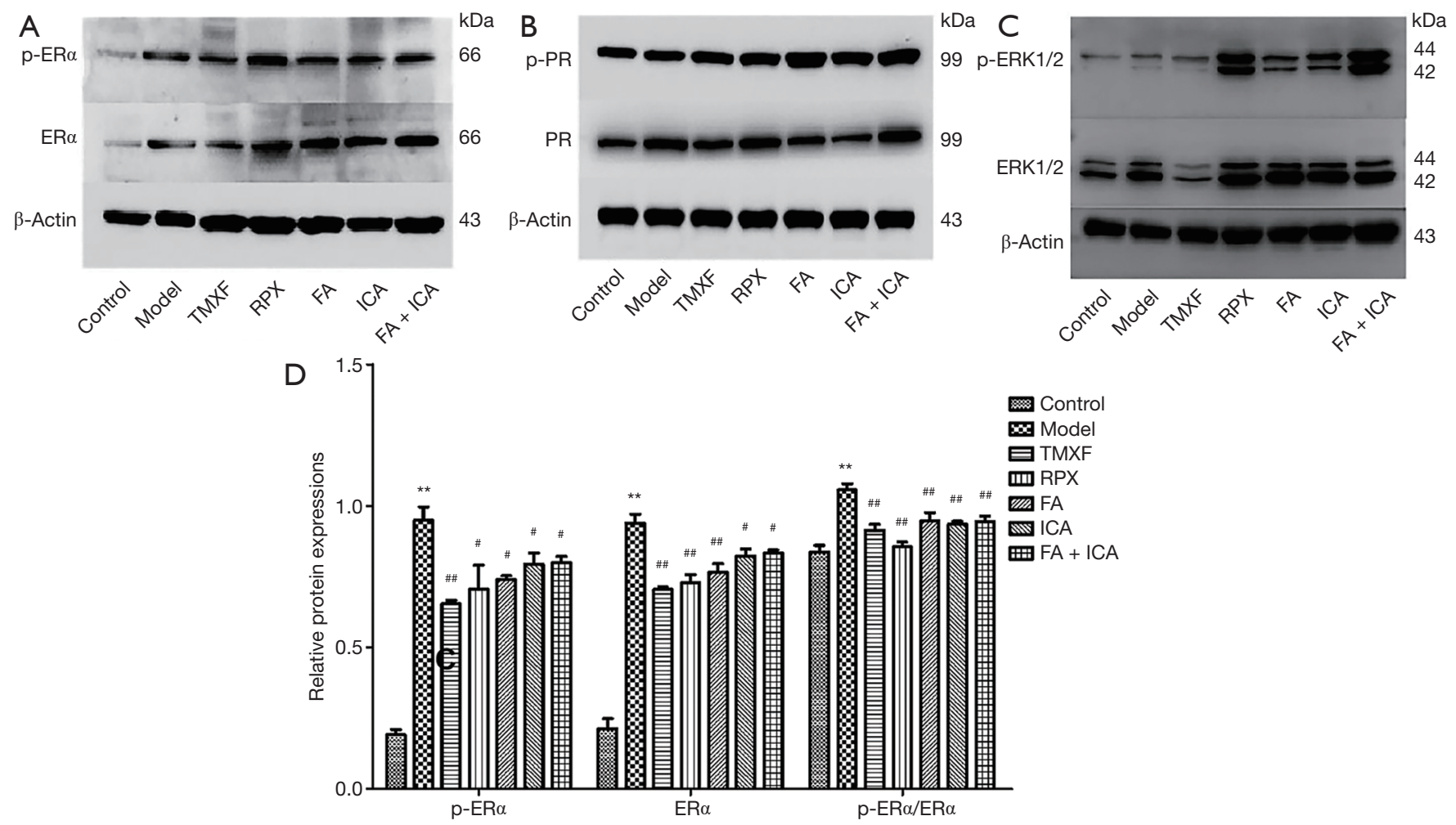



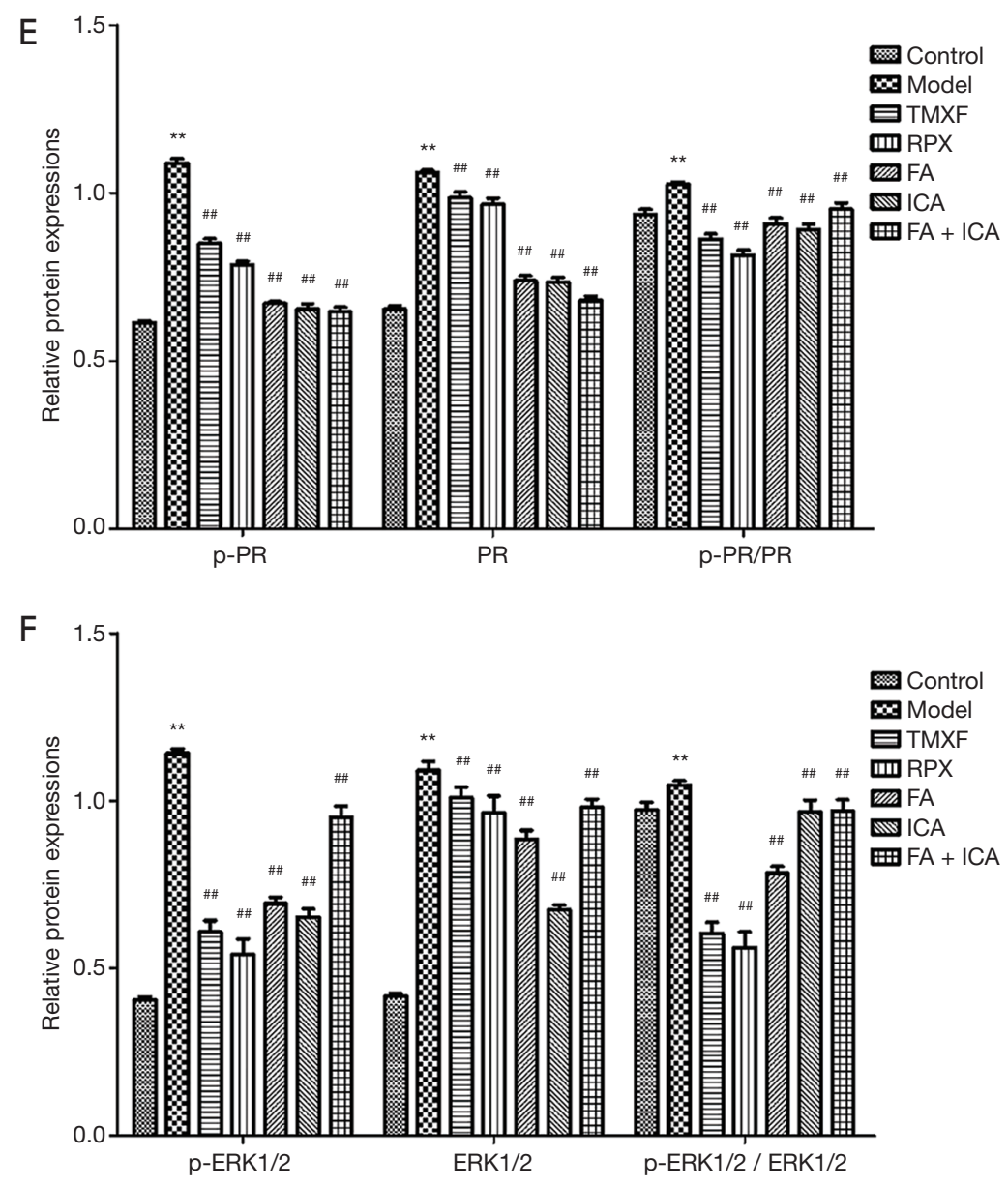

Figure 7 Effects of ferulic acid and icariin on the protein expressions in the mammary glands of rats in each group $(\bar{x} \pm \mathrm{s}, \mathrm{n}=10)$. (A) $\mathrm{p}$-ER $\alpha$ and ER $\alpha$; (B) p-PR and PR; (C) p-ERK1/2 and ERK1/2; (D) p-ER $\alpha, E R \alpha$ and p-ER $\alpha / E R \alpha ;(E)$ p-PR, PR and p-PR/PR; (F) p-ERK1/2, ERK1/2 and $\mathrm{p}-\mathrm{ERK} 1 / 2 / \mathrm{ERK} 1 / 2 .{ }^{* *} \mathrm{P}<0.01$ vs. blank group; ${ }^{\#} \mathrm{P}<0.05$ and ${ }^{\# \#} \mathrm{P}<0.01$ vs. model group.

However, the levels of $\mathrm{P}$ and estrogen were significantly down-regulated after treatment with FA, ICA, and their combination. All of the above-mentioned indexes of the MGH rats model group had a good recovery, including down-regulated expression levels of E2, LH, PRL, and $\mathrm{T}$ and the ratio of E2/P, and up-regulated levels of $\mathrm{P}$ and estrogen. These outcomes confirmed that FA and ICA have a certain regulatory effect on the levels of sex hormones in MGH model rats.

It is well known that the balance between $\mathrm{E} 2$ and $\mathrm{P}$ and their receptors, ER and PR, play important biological roles. Whenever E2 or P are absolutely or relatively boosted or attenuate $\mathrm{d}$, they could lose the function of restricting E2 and protecting breast tissue, and also stimulate breast tissue to constantly up-regulate estrogen, thereby ultimately leading to the overexpression of ER $\alpha$ and PR.
The overexpression of ER $\alpha$ and PR proteins could cause proliferative diseases of breast. ER $\alpha$ has been recommended as a marker to distinguish hormone dependence or nonhormone dependence as it promotes cell proliferation of the breast and other tissues.

We detected the mRNA and protein expressions of ER $\alpha$ and PR by RT-PCR and Western blotting. Our outcomes exhibited that ER $\alpha, P R, p-E R \alpha$, and $p-P R$ in the model group were obviously higher than those in the blank matched group. After treatment with FA, ICA, and their combination, $\mathrm{ER} \alpha$ and $\mathrm{PR}$ in the model group were notably down-regulated, implying that there was a close correlation between the hyperplasia of mammary glands and the overexpression of ER $\alpha$ and PR. The down-expression of $\mathrm{ER} \alpha$ and $\mathrm{PR}$ can reduce the sensitivity of breast tissue to $\mathrm{E} 2$, which can be implemented as one of the treatment 
options for breast hyperplasia (2).

ERK, including ERK1 and ERK2, is the signaling pathway of cell differentiation, proliferation, and other reactions, and plays a key role in the regulation of cell growth, division, proliferation, apoptosis, and other physiological processes. Its main role is to transfer extracellular signals to the nucleus. The continuous activation of ERK could up-regulate estrogen, which promotes the proliferation and migration of tumor cells. $\mathrm{P}-\mathrm{ERK} 1 / 2$ is an active form of ERK1/2, which could be transferred into the nucleus and regulate specific genes through the phosphorylation and activation of transcription factors. The ERK signaling mode is as follows: growth factor/hormone $\rightarrow$ receptor $\rightarrow$ ERK1 $\rightarrow$ ERK2. Our experiment exhibited that ERK1/2 level in the mammary gland tissue of the model group was significantly higher compared to the blank matched group, which is consistent with the outcomes of the mitogen-activated protein kinase (MAPK) expression analysis of 37 cases of mammary gland diseases by Sivaraman et al. After treatment with FA and ICA, the overexpression of ERK1/2 distinctly suppressed. This demonstrated that FA and ICA could inhibit ERK1/2 protein overexpression in the mammary gland tissue of MGH rats.

However, the boosted protein level was not equal to the increase in its activity, and thus, in this experiment, we detected activated ERK1/2, namely p-ERK1/2, in the mammary gland tissues of rats in each group. The outcomes exhibited that $\mathrm{p}$-ERK1/2 in the mammary gland tissues of the model group was obviously higher than that of the blank matched group. However, p-ERK1/2 level attenuate $\mathrm{d}$ in varying degrees after treatment with FA, ICA, and their combination. Together, these outcomes further substantiate that p-ERK1/2 and ERK1/2 play an important role in breast hyperplasia (16-18).

\section{Conclusions}

In short, FA, ICA, and their combination provided a good recovery in the numbers of lobules, numbers of acinars, and lobule volumes. Meanwhile, treatment with FA, ICA, and their combination down-regulated the levels of LH, PRL, $\mathrm{T}$, and E2 in serum, and up-regulated the contents of FSH and $\mathrm{P}$ serum, and also suppressd the protein up-expression of ER $\alpha, \mathrm{PR}, \mathrm{ERK} 1, \mathrm{ERK} 2, \mathrm{p}-\mathrm{ER} \alpha, \mathrm{p}-\mathrm{PR}, \mathrm{p}-\mathrm{ERK} 1 / 2$ in $\mathrm{MGH}$ rats. Our outcomes provide an overview of the mechanism of FA and ICA in the treatment of estrogeninduced breast hyperplasia via regulation of the ERK signaling pathway, and offer a new direction for guiding clinical application, especially for estrogen-dependent MGH patients.

\section{Acknowledgments}

Funding: None.

\section{Footnote}

Reporting Checklist: The authors have completed the ARRIVE reporting checklist. Available at http://dx.doi. org/10.21037/atm-21-656

Data Sharing Statement: Available at http://dx.doi. org/10.21037/atm-21-656

Conflicts of Interest: Both authors have completed the ICMJE uniform disclosure form (available at http://dx.doi. org/10.21037/atm-21-656). The authors have no conflicts of interest to declare.

Ethical Statement: The authors are accountable for all aspects of the work in ensuring that questions related to the accuracy or integrity of any part of the work are appropriately investigated and resolved. All experimental protocols were approved by the Institutional Animal Care and Use Committee at the Liaoning University of Traditional Chinese Medicine and in accordance with the National Institutes of Health guidelines for the Care and Use of Laboratory Animals.

Open Access Statement: This is an Open Access article distributed in accordance with the Creative Commons Attribution-NonCommercial-NoDerivs 4.0 International License (CC BY-NC-ND 4.0), which permits the noncommercial replication and distribution of the article with the strict proviso that no changes or edits are made and the original work is properly cited (including links to both the formal publication through the relevant DOI and the license). See: https://creativecommons.org/licenses/by-nc-nd/4.0/.

\section{References}

1. Marchant DJ. Benign breast disease . Obstet Gynecol Clin North Am 2002;29:1-20.

2. Li X, Wang Z, Wang Y, et al. Anti-hyperplasia Effects of Total Saponins From Phytolaccae Radix in Rats 
With Mammary Gland Hyperplasia via Inhibition of Proliferation and Induction of Apoptosis . Front Pharmacol 2018;9:467.

3. Donaldson A R, Mccarthy C, Goraya S, et al. Breast cancer risk associa ted with atypical hyperplasia and lobular carcinoma in situ initially diagnosed on core-needle biopsy. Cancer 2018;124:459-65.

4. Li H T, Liu HH, Yang YX, et al. Therapeutic Effects of a Traditional Chinese Medicine Formula plus Tamoxifen vs. Tamoxifen for the Treatment of Mammary Gland Hyperplasia: A Meta-Analysis of Randomized Trials. Front Pharmacol 2018;9:45.

5. Li X, Xin P, Wang C, et al. Mechanisms of Traditional Chinese Medicine in the Treatment of Mammary Gland Hyperplasia. Am J Chin Med, 2017, 45(3): 443-458.

6. Jiang C, Guo J, Wang Z, et al. Decursin and decursinol angelate inhibit estrogen-stimulated and estrogenindependent growth and survival of breast cancer cells. Breast Cancer Res 2007;9:R77.

7. Xue L, Wang Y, Jiang Y, et al. Comparative effects of erxian decoction, epimedium herbs, and icariin with estrogen on bone and reproductive tissue in ovariectomized rats. Evid Based Complement Alternat Med 2012;2012:241416.

8. Wang L, Zhao D, Di L, et al. The anti-hyperplasia of mammary gland effect of Thladiantha dubia root ethanol extract in rats reduced by estrogen and progestogen. J Ethnopharmacol 2011;134:136-40.

9. Livak KJ, Schmittgen TD. Analysis of relative gene expression data using real-time quantitative PCR and the 2(-Delta Delta C (T)) Method. Methods 2001;25:402-8.

10. Chang CJ, Chiu JH, Tseng LM, et al. Modulation of HER2 expression by ferulic acid on human breast cancer

Cite this article as: $\mathrm{Li} \mathrm{X}$, Shi G. Therapeutic effects and mechanism of ferulic acid and icariin in mammary gland hyperplasia model rats via regulation of the ERK pathway. Ann Transl Med 2021;9(8):666. doi: 10.21037/atm-21-656
MCF7 cells. Eur J Clin Invest 2006;36:588-96.

11. Cheng X, Tan S, Duan F, et al. Icariin induces apoptosis by suppressing autophagy in tamoxifen-resistant breast cancer cell line MCF-7/TAM. Breast Cancer 2019;26:766-75.

12. Yang J, Li Y, Wu J, et al. Efficacy of moxibustion by stimulating acupoints of Danzhong (CV 17) and Ganshu (BL 18) on hyperplasia of mammary gland in rats. J Tradit Chin Med 2018;38:76-82.

13. Zheng J, Zhao Y, Wang Y, et al. The infrared radiation temperature characteristic of acupoints of mammary gland hyperplasia patients. Evid Based Complement Alternat Med 2013;2013:567987.

14. Guan HL, Wang Y, Gui YF, et al. Effect of Chinese herbal medicine compound on breast hyperplasia: A protocol of systematic review. Medicine (Baltimore) 2020;99:e23463.

15. Chang XJ, Zhou J, Zhang S, et al. Effects of guizhi fuling capsule on sex hormone levels and breast issue morphology of mammary gland hyperplasia model rats. Zhongguo Zhong Yao Za Zhi 2014;39:4139-42.

16. Sun L, Guo D, Liu Q, et al. Efficacy of Lubeikangru formulation in mice with hyperplasia of the mammary glands induced by estrogen and progesterone. J Tradit Chin Med 2019;39:174-80.

17. Shan B, Li W, Yang SY, et al. Estrogen up-regulates MMP2/9 expression in endometrial epithelial cell via VEGF-ERK1/2 pathway. Asian Pac J Trop Med 2013;6:826-30.

18. Sivaraman VS, Wang H, Nuovo GJ, et al. Hyperexpression of mitogen-activated protein kinase in human breast cancer. J Clin Invest 1997;99:1478-83.

(English Language Editor: A. Kassem) 